\title{
Genotype-Specific Detection of Ferret Coronavirus by Conventional and Real-Time Reverse Transcription Polymerase Chain Reaction
}

\author{
Annabel G. Wise, Matti Kiupel, and Roger K. Maes
}

\begin{abstract}
Ferret coronavirus is associated with two disease presentations in ferrets, namely, epizootic catarrhal enteritis and a feline infectious peritonitis (FIP)-like systemic disease. In this chapter, we describe conventional and real-time one-step reverse transcription polymerase chain reaction assays that are routinely used in our laboratory to detect either genotype 1 or genotype 2 ferret coronavirus in clinical specimens. These assays were designed based upon the conserved spike gene sequence difference found between three strains of ferret systemic coronavirus and three strains of ferret enteric coronavirus. Recent literature evidence indicates that pathotype is not associated with a specific genotype, and therefore, it is important to test for both genotypes either in enteric or systemic disease.
\end{abstract}

Key words Ferret coronavirus, Conventional RT-PCR, Real-time RT-PCR, Molecular diagnostic assay

\section{Introduction}

Epizootic catarrhal enteritis (ECE), an enteric disease of domestic ferrets was first described in the USA in 1993 [1]. Clinically, the disease is characterized by a foul-smelling bright green diarrhea with high mucus content, lethargy, anorexia, and vomiting. Morbidity approaches $100 \%$, but mortality is usually below $5 \%$, with juvenile ferrets often developing only mild disease. ECE was found to be associated with an alphacoronavirus, designated ferret enteric coronavirus (FRECV) [2]. This disease or the enteric coronavirus agent associated with it has since spread in the USA and other countries worldwide [3-5]. Close to a decade after the recognition of ECE, a systemic disease, characterized by feline infectious peritonitis (FIP)-like clinical signs and lesions, began to emerge in ferrets across the USA and Europe [6-9]. Clinical findings include anorexia, weight loss, diarrhea and the presence of

Leyi Wang (ed.), Animal Coronaviruses, Springer Protocols Handbooks,

DOI 10.1007/978-1-4939-3414-0_16, @ Springer Science+Business Media New York 2016 
large palpable intra-abdominal masses. A marked resemblance to FIP is the gross observation of widespread whitish nodules on serosal surfaces and within the parenchyma of abdominal and thoracic organs. A systemic pyogranulomatous inflammation is the consistent histologic lesion observed in the affected organs, reminiscent of FIP. The agent associated with this disease, was found to be another alphacoronavirus, designated, ferret systemic coronavirus or FRSCV, and is most closely related to $\operatorname{FRECV~}[6,10]$. The disease continues to spread worldwide with more recent reports from the UK, France and Japan [11-14].

Comparative sequence analysis of the distal one-third of the genomes of one FRSCV and one FRECV strain [10] showed that these two viruses share at least $96 \%$ nucleotide sequence identities in the membrane, nucleocapsid and non-structural protein genes, ORFs 3 and $7 \mathrm{~b}$. However, their spike (S) proteins showed only $79.6 \%$ amino acid sequence identity. This allowed the development of two $S$ genotype-specific conventional [10], as well as realtime RT-PCR assays [15] for routine detection of these viruses in our laboratory. Limited preliminary data have shown that genotype l (FRSCV-like) ferret coronaviruses were found associated with the systemic type of illness while genotype 2 (FRECV-like) ferret coronaviruses were detected in cases of ECE [10]. Recent literature evidence indicates that there is no association between the $S$ genotype and virus pathotype $[4,5]$. The differentiating genotype-specific RT-PCR assays were recently used in a study that determined the prevalence of coronavirus among domestic ferrets in Japan [5]. The investigators noted that the majority of ferrets that were shedding the genotype 1 ferret coronavirus in feces were not ill with the systemic disease and that some were even asymptomatic. In the Netherlands, partial spike gene sequence analysis reported by Provacia et al. [4] showed that genotype 1 ferret coronavirus strains were also found present in feces of asymptomatic ferrets. These findings bring to mind the "in vivo mutation" theory proposed by Chang et al. [16] and Pedersen [17] for FIPinducing feline coronavirus strains. It may well be the case for ferret coronaviruses that the virus commonly found in normal feces may just be the "precursor" to a more pathogenic strain. Wise et al. [10] noted the presence of a truncated 3c-like protein gene in two out of three genotype 1 strains identified in ferrets with systemic disease, reminiscent of the $3 c$ gene mutations identified in FIP viruses in cats [16-18].

Polymerase chain reaction (PCR) is a method to amplify a fragment of double-stranded DNA to millions of copies, based upon repeated cycles of double-stranded DNA template denaturation, primer annealing and elongation. A primer is a short singlestranded DNA sequence, also called an oligonucleotide, that "primes" the reaction at the appropriate annealing temperature by binding to the complementary sequence of the denatured DNA 
target. Using the deoxyribonucleotides (dNTPs) in the reaction, the Taq polymerase enzyme then catalyzes the polymerization of nucleotides to polynucleotides beginning at the $3^{\prime}$ end of the primer in the elongation step. Reverse transcription polymerase chain reaction (RT-PCR) is used when the original target template is RNA, such that the RNA is first reverse-transcribed into "copy DNA," or cDNA, by the reverse transcriptase enzyme. The cDNA is then amplified in the PCR step. Conventional PCR/RT-PCR [19-22] requires the visualization of the amplified DNA or the PCR product, in an agarose gel matrix submerged in buffer through the process of electrophoresis. Electrophoresis subjects the PCR product to an electric current flow in the buffer that causes the DNA to migrate through the gel matrix according to its molecular weight. The PCR product is stained with an intercalating dye that fluoresces upon exposure to UV light, enabling its visualization alongside a DNA size marker ladder.

In real-time PCR/RT-PCR [19-22], the amplified DNA or the amplicon, is detected and recorded in "real-time" during the assay itself. With a hydrolysis probe-based real-time PCR, also called a "Taqman"-probe based assay, the amplification of DNA in every cycle results to a steady buildup of fluorescence signal in the reaction that can be detected using a specialized thermocycler with a built-in real-time nucleic acid detection system (e.g., Cepheid SmartCycler system). The probe, an essential component of the reaction mix, is a synthetic oligonucleotide with a sequence complementary to the target DNA flanked by the primers. The probe is labeled at its $5^{\prime}$ end with a fluorescent reporter dye (e.g., FAM) and with a fluorescence quencher (e.g., BHQ-1) at its $3^{\prime}$ end. There is no fluorescent signal emitted as long as the probe remains intact. In the presence of the specific target DNA in the reaction, after the primers and probe anneal to their complementary sequence, polymerization takes place in the elongation phase of the PCR cycle, during which the probe is degraded via the $5^{\prime}$ exonuclease activity of the Taq DNA polymerase. Probe degradation leads to the release of the reporter dye from the probe and from its proximity to the quencher molecule, resulting to the accumulation of fluorescence signal in the reaction mix at every PCR cycle.

\section{Materials}

\subsection{RNA Extraction}

1. QIAGEN RNeasy Mini Kit.

2. $\beta$-mercaptoethanol ( $\beta$-ME).

3. Ethanol (EtOH), 96-100\% grade.

4. $70 \% \mathrm{EtOH}$ (prepared by adding three parts molecular grade water to seven parts $100 \% \mathrm{EtOH}$ ).

5. RNase/DNase-free water (molecular grade water). 
2.2 One-Step Reverse Transcription Polymerase Chain Reaction

6. Clinical samples: feces; tissues.

7. 0.1 M phosphate buffered saline (PBS).

8. Micropipettes, sterile and RNAse-free pipette tips (filtered tips are preferable), autoclaved/sterile microcentrifuge tubes (1.5-2 ml capacity), microcentrifuge tube rack.

9. Disposable gloves; protective clothing and eyewear.

1. QIAGEN OneStep RT-PCR Kit.

Components of the kit:

(a) $5 \times$ OneStep RT-PCR Buffer.

(b) dNTP Mix (containing $10 \mathrm{mM}$ of each dNTP).

(c) OneStep RT-PCR Enzyme Mix (contains HotStarTaq DNA Polymerase and Omniscript and Sensiscript reverse transcriptases).

(d) RNase/DNase-free water.

2. $25 \mathrm{mM} \mathrm{MgCl}_{2}$ solution.

3. Genotype 1-specific (Gl) primers (see Note 1).

(a) $20 \mu \mathrm{M}$ Gl forward primer, 5' ${ }^{\prime}$-CTGGTGTTTGTGCAAC ATCTAC-3'.

(b) $20 \mu \mathrm{M}$ Gl reverse primer, 5'-TCTATTTGCACAAAAT CAGACA-3',

4. Genotype 2-specific (G2) primers (see Note 1).

(a) $20 \mu \mathrm{M}$ G2 forward primer, 5'-GGCATTTGTTTTGATA ACGTTG-3'.

(b) $20 \mu \mathrm{M}$ G2 reverse primer, 5' -CTATTAATTCGCACGAA ATCTGC-3'.

5. Known genotype 1 or 2 ferret coronavirus positive RNA (positive control).

6. RNase/DNase-free water (negative control).

7. Micropipettes, filtered tips, sterile RNAse-free microcentrifuge tubes, $0.2 \mathrm{ml}$ PCR tubes, and PCR tube rack.

8. PCR tube mini-centrifuge.

9. Thermocycler (ABI 2720, Applied Biosystems).

2.3 Agarose Gel Electrophoresis
1. 50 $\times$ TAE (Tris-acetate-EDTA) buffer.

2. Agarose powder.

3. 100 bp DNA Ladder (New England Biolabs).

4. $6 \times$ gel loading buffer (this comes with the DNA ladder).

5. Ethidium bromide, $10 \mathrm{mg} / \mathrm{ml}$. 
6. Gel casting tray (for $100 \mathrm{ml}$ gel volume) and comb (10-slot comb) ( see Note 2).

7. Agarose gel electrophoresis apparatus.

8. Power supply.

9. UV light box/transilluminator; UV protective face shield.

10. Gel photography equipment.

2.4 Taqman Probebased One-Step Real-Time (rt) RT-PCR
1. AgPath ID One-Step RT-PCR Kit (Applied Biosystems, ThermoFisher).

2. Genotype 1-specific (Glrt) primers and probe (see Notes $\mathbf{1}$ and $\mathbf{3}$ ).

(a) $20 \mu \mathrm{M}$ Glrt forward primer, 5'-GATGTGTCGTTGACK TTRTT- 3 '.

(b) $20 \mu \mathrm{M}$ Glrt reverse primer, 5'-TGGTGCAGCTTTCTA TTTGC-3'.

(c) $6 \mu \mathrm{M}$ Glrt probe, $5^{\prime}$-(FAM)ACRCCGCGTACAATGTAC GAACC(BHQ-1)-3' (FAM, 6-carboxy-fluorescein; BHQ-1, blackhole quencher 1$)$.

3. Genotype 2-specific (G2rt) primers and probe (see Notes 1, 4 and 5 ).

(a) $20 \mu \mathrm{M}$ G2rt forward primer, 5'-GGCATTTGTTTTG ATAACGTTG-3'.

(b) $20 \mu \mathrm{M}$ G2rt reverse primer, 5'-CTATTAATTCGCACGA AATCTGC-3'.

(c) $10 \mu \mathrm{M}$ G2rt probe, 5'-(FAM)CTCATACATAGTAC GTG(MGB-NFQ)-3' (FAM, 6-carboxy-fluorescein; MGB-NFQ, minor-groove binding probe-nonfluorescent quencher).

4. Real-time PCR instrument (SmartCycler II, by Cepheid, Inc.); computer and software.

5. SmartCycler PCR reaction tubes, SmartCycler reaction tube rack, Smart Tube benchtop centrifuge.

\section{Methods}

3.1 RNA Extraction 1. Reconstituting reagents in a new QIAGEN RNeasy Mini Kit (see Note 6).

(a) Add $10 \mu \mathrm{l}$ of $\beta$-ME (see Note 7 ) for every $10 \mathrm{ml}$ of buffer RLT (lysis buffer) (see Note 8).

This lysis buffer is stable at room temperature for 1 month after the addition of $\beta$-ME. 
(b) Add 4 volumes of ethanol to the new bottle of RPE buffer (supplied as a concentrate), according to the manufacturer's instructions as indicated on the bottle to obtain a working solution.

2. Sample preparation ( see Note 9):

(a) Prepare $\sim 10 \%$ fecal homogenate by diluting feces in $0.1 \mathrm{M}$ PBS. Clarify the sample by centrifuging for $5 \mathrm{~min}$ at $2500 \mathrm{rpm}(\sim 580 \mathrm{rcf}$ for a 24 -well microcentrifuge (e.g. Eppendorf Centrifuge 5417C)).

(b) For tissues, prepare $\sim 10 \%$ tissue homogenate in $0.1 \mathrm{M}$ PBS (see Note 10).

3. Pipet $140 \mu \mathrm{l}$ of sample into a microcentrifuge tube.

4. Add $560 \mu \mathrm{l}$ of buffer RLT with $\beta$-ME to the sample. Mix gently by pipetting.

5. Add $700 \mu \mathrm{l}$ of $70 \% \mathrm{EtOH}$ to the lysed sample. Mix gently by pipetting.

6. Transfer $700 \mu \mathrm{l}$ of the sample solution to an RNeasy mini column supplied with a 2 -ml filtrate collection tube.

7. Close the column and centrifuge for $30 \mathrm{~s}$ at 10,000 rpm. Discard the filtrate and reuse the collection tube in step 8.

8. Transfer the remaining sample solution $(\sim 700 \mu \mathrm{l})$ to the same RNeasy mini column and centrifuge for $30 \mathrm{~s}$ at 10,000 rpm. Discard the filtrate and reuse the collection tube in step 9.

9. Add $700 \mu \mathrm{l}$ of buffer RWl (see Note 11) to the RNeasy mini column. Close the column and centrifuge for $30 \mathrm{~s}$ at $10,000 \mathrm{rpm}$. Discard the filtrate and the collection tube.

10. Place the RNeasy mini column into a new $2 \mathrm{ml}$ collection tube. Add $500 \mu \mathrm{l}$ of buffer RPE (previously reconstituted with $\mathrm{EtOH}$ ) to the column for a first wash. Close the column and centrifuge the column for $30 \mathrm{~s}$ at 10,000 rpm. Discard the filtrate and reuse the collection tube in step 11.

11. Add another $500 \mu \mathrm{l}$ of buffer RPE to the RNeasy column for the second wash. Close the column and centrifuge for $2 \mathrm{~min}$ at $10,000 \mathrm{rpm}$. Discard the filtrate and collection tube.

12. Place the RNeasy mini column with the cap closed into a new $2 \mathrm{ml}$ collection tube. Dry spin the column for $1 \mathrm{~min}$ at 14,000 rpm. Residual RPE buffer will be removed from the column ( see Note 12). Discard the collection tube.

13. To elute the RNA, place the RNeasy mini column into a new microcentrifuge tube. Pipet $100 \mu \mathrm{l}$ of RNase/DNase-free water into the column close to the silica-gel membrane. Close the column, let stand for $1 \mathrm{~min}$ at room temperature, then centrifuge for $1 \mathrm{~min}$ at 10,000 rpm. Discard the column.

14. Put the microcentrifuge tube with the extracted RNA on ice (see Note 13). The RNA sample is now ready to be tested. 
3.2 One-Step RT-PCR Assay
Store the RNA in refrigeration temperature if testing within $24 \mathrm{~h}$. Store it in -20 or $-80{ }^{\circ} \mathrm{C}$ if testing will be delayed for more than $24 \mathrm{~h}$.

1. Working in a designated "clean" PCR station (see Note 14), thaw the OneStep RT-PCR kit reagents and working stock primers on ice. In a sterile microcentrifuge tube, prepare the master mix for the number of reactions needed per genotype test according to Tables 1 and 2. Total number of reactions $(N)$ equals the number of samples to be tested, plus two more for positive and negative controls, then add to this subtotal $10 \%$ more reactions for overage allowance.

Table 1

Components of RT-PCR master mix (genotype 1-specific)

\begin{tabular}{|llll}
\hline Master mix reagent & $\begin{array}{l}\text { Volume per } \\
\text { reaction }(\boldsymbol{\mu l})\end{array}$ & $\begin{array}{l}\text { Volume for } \boldsymbol{N} \\
\text { reactions }(\boldsymbol{\mu l})\end{array}$ & $\begin{array}{l}\text { Final } \\
\text { concentration }\end{array}$ \\
\hline 5× QIAGEN OneStep RT-PCR buffer & 10 & $10 \times N$ & $1 \times$ \\
\hline dNTP mix & 2 & $2 \times N$ & $0.4 \mathrm{mM}$ \\
\hline $25 \mathrm{mM} \mathrm{MgCl} 2$ & 2.5 & $2.5 \times N$ & $1.25 \mathrm{mM}$ \\
\hline Gl forward primer, $20 \mu \mathrm{M}$ & 1.25 & $1.25 \times N$ & $0.5 \mu \mathrm{M}$ \\
\hline Gl reverse primer, $20 \mu \mathrm{M}$ & 1.25 & $1.25 \times N$ & $0.5 \mu \mathrm{M}$ \\
\hline QIAGEN OneStep Enzyme Mix & 2 & $2 \times N$ & - \\
\hline RNase-free water & 33 & $33 \times N$ & - \\
\hline Total & 45 & & \\
\hline
\end{tabular}

Table 2

Components of RT-PCR master mix (genotype 2-specific)

\begin{tabular}{llll}
\hline Master mix reagent & $\begin{array}{l}\text { Volume per } \\
\text { reaction }(\boldsymbol{\mu l})\end{array}$ & $\begin{array}{l}\text { Volume for } \boldsymbol{N} \\
\text { reactions }(\boldsymbol{\mu l})\end{array}$ & $\begin{array}{l}\text { Final } \\
\text { concentration }\end{array}$ \\
\hline 5× QIAGEN OneStep RT-PCR buffer & 10 & $10 \times N$ & $1 \times$ \\
\hline dNTP mix & 2 & $2 \times N$ & $0.4 \mathrm{mM}$ \\
\hline $25 \mathrm{mM} \mathrm{MgCl}{ }_{2}$ & 2.5 & $2.5 \times N$ & $1.25 \mathrm{mM}$ \\
\hline G2 forward primer, $20 \mu \mathrm{M}$ & 1.25 & $1.25 \times N$ & $0.5 \mu \mathrm{M}$ \\
\hline G2 reverse primer, $20 \mu \mathrm{M}$ & 1.25 & $1.25 \times N$ & $0.5 \mu \mathrm{M}$ \\
\hline QIAGEN OneStep RT-PCR Enzyme Mix & 2 & $2 \times N$ & - \\
\hline RNase-free water & 33 & $33 \times N$ & - \\
\hline Total & 45 & & \\
\hline
\end{tabular}




\subsection{Agarose Gel Electrophoresis}

2. Mix the contents of the tube by pipetting gently. Keep the master mix tube on ice.

3. Dispense $45 \mu \mathrm{l}$ of master mix to each $0.2 \mu \mathrm{l}$ PCR tube. For the negative control, add $5 \mu \mathrm{l}$ of sterile RNase/DNase-free water to the last PCR tube, then close the tube (see Note 15).

4. Transfer to the template addition area/hood. Keeping a record of the order of samples and controls, add $5 \mu$ of each sample RNA (template) to a PCR tube, closing the tube cap after each template addition.

5 . Add $5 \mu$ l of positive control RNA (known positive genotype 1 or 2 ferret coronavirus RNA) to the last open tube (see Note 16). Close the cap.

6. Centrifuge the tubes briefly.

7. Place the tubes in the thermocycler and run the RT-PCR reaction according to the cycling protocol shown in Table 3.

8 . When the run is completed, analyze the PCR products by agarose gel electrophoresis. The products may be kept in the refrigerator or frozen for short-term holding.

1. Preparing $1 \mathrm{l}(1000 \mathrm{ml})$ of $\mathrm{l} \times$ TAE buffer from a $50 \times$ TAE stock solution:

(a) Pour $20 \mathrm{ml}$ of $50 \times$ concentrated TAE buffer into a 11 graduated cylinder.

(b) Fill the cylinder with deionized water up to the 11 line, making a $l \times$ final concentration of TAE buffer.

2. Preparing a working stock solution of 100 bp DNA ladder with pre-added loading dye:

Table 3

Cycling conditions for RT-PCR

\begin{tabular}{|lll}
\hline Step & Temperature $\left({ }^{\circ} \mathrm{C}\right)$ & Time \\
\hline 1. Reverse transcription & 50 & $30 \mathrm{~min}$ \\
\hline 2. Heat activation/inactivation & 95 & $15 \mathrm{~min}$ \\
\hline 3. PCR cycling $(40$ cycles $)$ & & \\
\hline \multicolumn{1}{|c|}{ Denaturation } & 94 & $30 \mathrm{~s}$ \\
\hline Annealing & 55 & $30 \mathrm{~s}$ \\
\hline Extension & 72 & $30 \mathrm{~s}$ \\
\hline 4. Final Extension & 72 & $7 \mathrm{~min}$ \\
\hline 5. Hold & 4 & $\infty$ \\
\hline
\end{tabular}


(a) To a new tube of 100 bp DNA ladder, add $500 \mu$ l DNasefree water and $80 \mu \mathrm{l}$ of the $6 \times$ loading dye/buffer.

(b) Mix evenly by gently pipetting up and down.

3. Preparing a $2 \%$ agarose gel:

(a) Assemble the gel-casting tray on the gel-casting rack. Using a level indicator, make sure it is level. Position the gel comb on the tray slots.

(b) Weigh $2 \mathrm{~g}$ of agarose powder on a clean weighing paper or boat. In a $250 \mathrm{ml}$ Erlenmeyer flask, pour the $2 \mathrm{~g}$ agarose powder then add $100 \mathrm{ml}$ of $1 \times$ TAE buffer. Swirl the flask gently to mix.

(c) Microwave the flask on high for about 2 min or until the agarose is completely melted, with the solution bubbling and turning clear/transparent (see Note 17).

(d) After microwaving, add $5 \mu$ l of the ethidium bromide solution to the melted agarose. Grasping the flask with a heat-protective mitten, swirl the flask gently until the ethidium bromide is evenly distributed in the solution (see Note 18).

(e) Pour the gel solution into the gel tray and let stand for at least $45 \mathrm{~min}$ in room temperature or until the gel becomes solidified. The gel will have a thickness of about $0.8 \mathrm{~cm}$.

4. Remove the gel tray with the casted $2 \%$ gel from the casting rack. Gently lift the comb out of the gel (see Note 19).

5. Place the gel tray onto the electrophoresis tank at the correct orientation (the top of the gel next to the negative lead or cathode [black]). Pour enough $1 \times$ TAE buffer into the tank buffer chamber to submerge the gel with about $2-3 \mathrm{~mm}$ of buffer above the surface of the gel.

6. Add $10 \mu \mathrm{l}$ of the $6 \times$ gel loading dye to the $50 \mu \mathrm{l}$ PCR product in each tube. Mix evenly by gentle pipetting.

7. In the first well of the gel, load $30 \mu$ of the 100 bp DNA ladder working stock solution.

8. Load $50 \mu \mathrm{l}$ of each PCR product with the dye in the succeeding wells ( see Note 20).

9. Close the lid of the tank and connect the color-coded wires/ leads to the appropriate sockets of the power supply and the gel tank (black to black, red to red). DNA migrates toward the positive lead or anode (red).

10. Turn on the power supply. Set the voltage output to $100 \mathrm{~V}$. Run for approximately $45 \mathrm{~min}$ to $\mathrm{l} \mathrm{h}$ checking the dye level for adequate product migration time (see Note 21 ). 
11. When DNA migration is complete, turn off the power supply. Unplug the leads from the gel tank, lift the cover and remove the gel tray.

12. Set the gel on top of the UV transilluminator. Turn off the room light.

13. While wearing a UV protective face shield, turn the UV light on to visualize the gel.

14. The expected product sizes are: 157 bp for genotype 1 and 146 bp for genotype 2 ferret coronavirus (Fig. la, b).

15. Document the results with the photo-documentation instrument. Turn the UV light off when finished.
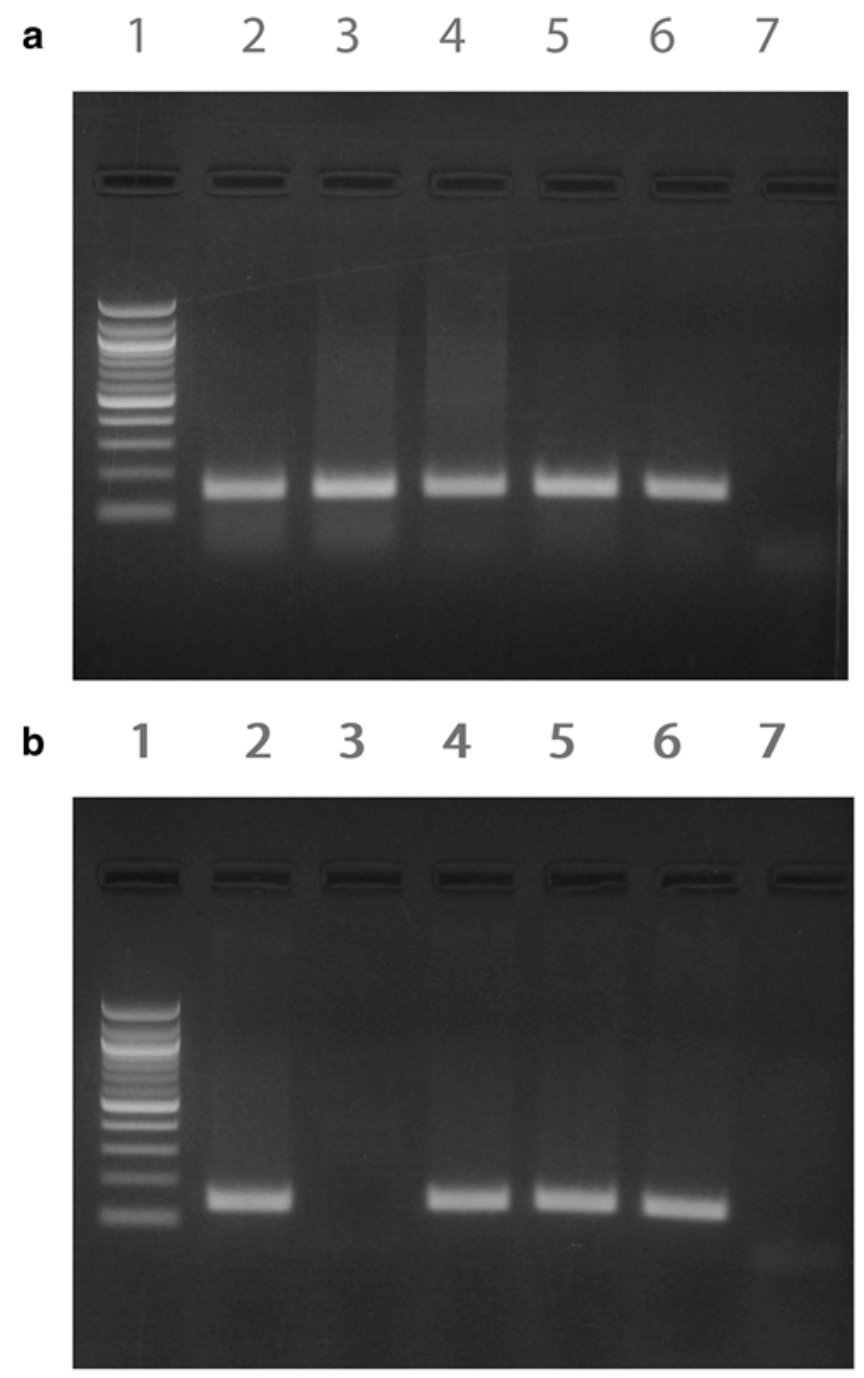

Fig. 1 Conventional ferret coronavirus RT-PCR. (a) Genotype 1 RT-PCR. Lanes: 1 , 100 bp DNA ladder; 2-5, positive samples; 6, positive control (157 bp); 7, negative control. (b) Genotype 2 RT-PCR. Lanes: 1, 100 bp DNA ladder; 2, 4, and 5, positive samples; 3 , negative sample; 6 , positive control (146 bp); 7 , negative control 


\subsection{Taqman Probe- Based One-Step Real-Time RT-PCR}

1. Turn on the computer and the SmartCycler machine. The SmartCycler block will display a lighted "0" at the bottom left corner of the top surface of the instrument.

2. Click on the SmartCycler software icon to start the program. If using only one SmartCycler block, it will be designated as block "A". The lighted " 0 " will switch to the letter designation (see Note 22). This confirms that the computer has established connection with the instrument.

3. Click "Define Graphs" located at the toolbar on the top of the screen (see Note 23).

(a) Select "FAM" under the Graph list, then select or check the box for the following options: Check "Automatically added to new Runs"; for "Graph Type" select Optics; for "Channels" select Ch 1; under "Show" check Primary Curve, Threshold (Horizontal) and Threshold Crossings (Vertical); for "Axes" select Fluorescence vs. Cycle. Click "Save Graph".

(b) Select "Temperature" under the Graph list. Then select or check the box for "Sample Temperature". Check "Automatically added to new Runs". Click "Save Graph".

4. Click "Define Protocols" located in the tool bar at the top of the screen. Click "New Protocol" at the bottom of the screen, then type a "Protocol Name" (e.g., Ferret Coronavirus $S$ Genotyping) and enter the cycling protocol parameters according to Table 4 . Save the protocol.

5. Click "Create a Run".

\section{Table 4}

Cycling conditions for real-time RT-PCR

\begin{tabular}{|llll}
\hline Step & Temperature $\left({ }^{\circ} \mathbf{C}\right)$ & Time & Optics \\
\hline${ }^{a} 1$. Reverse transcription & 45 & $10 \mathrm{~min}$ & Off \\
\hline $\begin{array}{l}\text { a2. Heat activation/inactivation } \\
\text { 3. PCR cycling }(45 \text { cycles })\end{array}$ & 95 & $15 \mathrm{~min}$ & Off \\
\hline${ }^{\mathrm{b} D e n a t u r a t i o n}$ & 94 & $10 \mathrm{~s}$ & Off \\
\hline${ }^{\mathrm{b}}$ Annealing & 55 & $30 \mathrm{~s}$ & On \\
\hline${ }^{\mathrm{b}}$ Extension & 72 & $10 \mathrm{~s}$ & Off \\
\hline
\end{tabular}

"In defining a protocol in the SmartCycler, enter these steps as "Stage 1 with 2-Temperature Cycle". Enter "1.6" under Deg/Sec column

bIn defining a protocol in the SmartCycler, enter these steps as "Stage 2 with 3-Temperature Cycle". Enter "1.6" under Deg/Sec column 
6. Assign a "Run Name".

7. Leave the Dye Set at the default setting, "FCTC25."

8. Click "Select Graphs" at the bottom of the screen. Under "All Graphs" on the left side of the screen, highlight "FAM" and "Temperature", then click the right-pointing arrow to transfer these graphs under "Selected Graphs" on the right. Click "OK". Unused graphs under "Selected Graphs", if present, may be deselected by highlighting the graphs then clicking the left-pointing arrow.

9. For Channel/Dye settings, leave FAM at the default Usage setting, "Assay". All other dyes/fluorophores (Cy3, TxR, and Cy5) may be set to "Unused" (see Note 24).

10. For Analysis Settings, set "Bkgnd Max Cycle" (background maximum cycle) at 28 and "Manual Thresh Fluor Units" (manual threshold fluorescence units) at 25. Leave the rest of the analysis settings at default.

11. Click "Add Remove Sites". Select the appropriate protocol from the protocol list. Select the "sites" or "wells" to be used (e.g., A1, A2, A3) depending on the number of samples to be run, plus two more sites for the positive and the negative controls.

12. Click the arrowhead symbol to add the sites to the selections column on the right. Click the "OK" button.

13. Enter the Sample IDs in the table.

14. Prepare the RT-PCR master mix according to Tables 5 or 6.

15. On a chilled SmartCycler reaction tube rack (see Note 25), put the appropriate number of SmartCycler reaction tubes needed

Table 5

Components of real-time RT-PCR master mix (genotype 1-specific)

\begin{tabular}{|llll}
\hline Master mix reagent & $\begin{array}{l}\text { Volume per } \\
\text { reaction }(\boldsymbol{\mu l})\end{array}$ & $\begin{array}{l}\text { Volume for } \boldsymbol{N} \\
\text { reactions }(\boldsymbol{\mu l})\end{array}$ & $\begin{array}{l}\text { Final } \\
\text { concentration }\end{array}$ \\
\hline $2 \times$ AgPath ID One-Step RT-PCR buffer & 12.5 & $12.5 \times N$ & $1 \times$ \\
\hline Enhancer & 1.67 & $1.67 \times N$ & - \\
\hline Glrt forward primer, $20 \mu \mathrm{M}$ & 0.62 & $0.62 \times N$ & $0.5 \mu \mathrm{M}$ \\
\hline Glrt reverse primer, $20 \mu \mathrm{M}$ & 0.62 & $0.62 \times N$ & $0.5 \mu \mathrm{M}$ \\
\hline Glrt probe, $6 \mu \mathrm{M}$ & 0.5 & $0.5 \times N$ & $120 \mathrm{nM}$ \\
\hline AgPath ID One-Step RT-PCR enzyme mix $1 \mu \mathrm{l}$ & 1 & $1 \times N$ & \\
\hline RNase-free water & 0.09 & $0.09 \times N$ & - \\
\hline Total & 17 & & \\
\hline
\end{tabular}


Table 6

Components of real-time RT-PCR master mix (genotype 2-specific)

\begin{tabular}{|llll}
\hline Master mix reagent & $\begin{array}{l}\text { Volume per } \\
\text { reaction }(\boldsymbol{\mu l})\end{array}$ & $\begin{array}{l}\text { Volume for } \boldsymbol{N} \\
\text { reactions }(\boldsymbol{\mu l})\end{array}$ & $\begin{array}{l}\text { Final } \\
\text { concentration }\end{array}$ \\
\hline $2 \times$ AgPath ID One-Step RT-PCR buffer & 12.5 & $12.5 \times N$ & $1 \times$ \\
\hline Enhancer & 1.67 & $1.67 \times N$ & - \\
\hline G2rt forward primer, $20 \mu \mathrm{M}$ & 0.62 & $0.62 \times N$ & $0.5 \mu \mathrm{M}$ \\
\hline G2rt reverse primer, $20 \mu \mathrm{M}$ & 0.62 & $0.62 \times N$ & $0.5 \mu \mathrm{M}$ \\
\hline G2rt probe, $10 \mu \mathrm{M}$ & 0.5 & $0.5 \times N$ & $200 \mathrm{nM}$ \\
\hline AgPath ID One-Step RT-PCR enzyme mix & 1 & $1 \times N$ & - \\
\hline RNase-free water & 0.09 & $0.09 \times N$ & - \\
\hline Total & 17 & & \\
\hline
\end{tabular}

for the run. Number each tube at the cap surface to keep track of the sample order.

16. Dispense $17 \mu \mathrm{l}$ of master mix into each tube. Add $8 \mu \mathrm{l}$ of sample RNA, positive control RNA, and RNAse-free water (no template control) into the appropriate tube, then cap each tube tightly.

17. Spin the tubes for $3-5$ s using the Smart Tube mini-centrifuge.

18. Load the tubes in the pre-selected SmartCycler sites/wells, then securely close the top cover of each site.

19. Click "Start Run". Run-time is approximately $1 \mathrm{~h}$ and $40 \mathrm{~min}$.

20. When the run is finished, the Results Table will show for each Site ID whether the sample is "positive" or "negative". Positive samples, including the positive control, will have a FAM Ct (cycle threshold) $>0$. Negative samples, including the negative control, will have a FAM Ct $=0.00$ (see Note 26).

21. These tabulated results should be confirmed by viewing the amplification curve, also known as growth curve, for each sample and control, by selecting "FAM" under the "Views" pane. A sample is truly positive when the plot of its fluorescence vs. cycle number produces a sigmoidal shaped amplification curve as it crosses the threshold setting and continues to generate increasing fluorescent signal until it plateaus or reaches the last cycle (Fig. 2). The amplification graph of a negative sample and the negative control will appear as a flat line (Fig. 2) (see Note 26). 


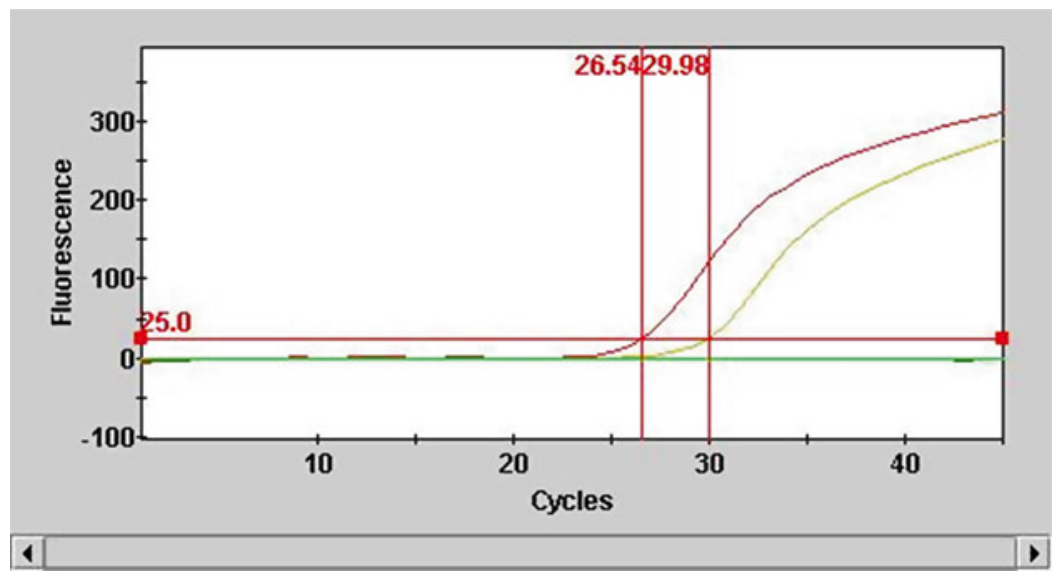

Fig. 2 Real-time PCR for ferret coronavirus genotype 1. Sigmoidal amplification curves generated by a positive sample $(\mathrm{Ct}=29.98)$ and a positive control $(\mathrm{Ct}=26.54)$. Manual threshold fluorescence is set at " 25 ", indicated by the red horizontal line. The negative control appears as a flat green line at the "0" fluorescence level

\section{Notes}

1. Commercially ordered primers come in a dried down state. The amount of the primer in nanomoles (nanomoles $\times 1000=$ picomoles $)$ is stated on the tube. For each new primer tube, divide the number of picomoles ( $\mathrm{pmol}$ ) by $200 \mathrm{pmol} / \mu \mathrm{l}$. The number derived equals the amount of sterile $1 \times$ TE (Tris EDTA) buffer or RNAse/DNAse-free water, in microliters, to be added to the tube to obtain a $10 \times$ primer stock of $200 \mu \mathrm{M}$ concentration. To obtain a $20 \mu \mathrm{M} \mathrm{l} \times$ working primer stock, dilute ( $1: 10) 5 \mu \mathrm{l}$ of the $10 \times$ stock in $45 \mu \mathrm{l}$ of RNAse/DNAse-free water. Store $10 \times$ primer stocks and $1 \times$ working stocks in $-20{ }^{\circ} \mathrm{C}$ or colder.

2. A smaller gel size $(50 \mathrm{ml})$ may be used with the appropriate comb size and electrophoresis tank. Adjust amount of agarose powder and TAE buffer volumes in step 3 of Sect. 3.3, accordingly.

3. A commercially ordered FAM/BHQ-1 labeled probe comes in a dried down state. The amount of probe in nanomoles (nanomoles $\times 1000=$ picomoles) is stated on the tube. Divide the number of picomoles by $120 \mathrm{pmol} / \mu \mathrm{l}$. The number derived equals the amount of sterile $1 \times \mathrm{TE}$ buffer, in microliters, to be added to the tube to obtain a $20 \times$ probe stock. To obtain a $6 \mu \mathrm{M} 1 \times$ working probe stock, dilute (1:20) $5 \mu \mathrm{l}$ of the $20 \times$ stock in $95 \mu \mathrm{l}$ of RNAse/DNAse-free water. Store probe stocks in amber-colored tubes (probes are light-sensitive) at $-20{ }^{\circ} \mathrm{C}$ or colder. Avoid freeze-thawing working probe stocks more than four times to prevent degradation of the probe. 
4. A MGB/NFQ-labeled probe can be ordered from ThermoFisher Scientific and is supplied as a $100 \mu \mathrm{M}$ solution. This is the $10 \times$ probe stock. To obtain a $10 \mu \mathrm{M} 1 \times$ working probe stock, dilute $5 \mu \mathrm{l}$ of the $10 \times$ stock solution in $45 \mu \mathrm{l}$ of RNAse/DNAse-free water. Use amber-colored tubes for the working stocks and store probes at $-20{ }^{\circ} \mathrm{C}$ or colder.

5. G2 rt primers have the same sequences as the G2 primers for conventional RT-PCR.

6. Refer to the RNeasy Mini Handbook for description of the RNeasy principle/technology, additional chemical safety information (e.g., how to obtain material safety data sheets online), troubleshooting tips, and general remarks on handling RNA.

7. $\beta$-ME is a toxic chemical that must be dispensed in a chemical fume hood. Always handle with gloves, protective clothing and eyewear (personal protective gear).

8. Buffer RLT contains guanidine thiocyanate. It is harmful by inhalation, in contact with skin, and if swallowed.

9. When handling fresh animal tissues and feces, personal protective gear must be worn at all times and work must take place in Biosafety Level (BSL) 2 containment using a BSL 2 hood with the HEPA-filter blower on. The blower may be turned off once the specimens are inactivated in the RLT lysis buffer.

10. For animals exhibiting FIP-like lesions, collect sections of grossly affected tissues (i.e., mesenteric adipose tissue and lymph nodes, lung, liver, and spleen). Tissue homogenization is optimally performed by rapid agitation in the presence of a bead or beads using a laboratory mixer mill. Alternatively (if a mixer mill is not available), $25 \mathrm{mg}$ of tissue can be directly disrupted and homogenized in $750 \mu \mathrm{l}$ of buffer RLT with $\beta$-ME in a microcentrifuge tube using a disposable RNAse-free pestle. The tube is then centrifuged for $5 \mathrm{~min}$ at $5000 \mathrm{rpm}(\sim 2300$ rcf for a 24-well microcentrifuge (i.e. Eppendorf Centrifuge $5417 \mathrm{C})$ to clarify the lysate. Transfer $700 \mu \mathrm{l}$ of the lysate into a fresh tube, then proceed directly to step 5 (addition of $70 \%$ EtOH) to continue with the RNA extraction.

11. Buffer RWI contains ethanol and therefore is flammable.

12. Removal of residual RPE buffer in this step is crucial. The wash buffer contains EtOH which is inhibitory to PCR.

13. Holding RNA samples at $4{ }^{\circ} \mathrm{C}$ or below prior to running the RT-PCR is very important to keep its integrity. This minimizes the chance of any trace contamination with ribonucleases (RNase enzymes) in the sample to be active and degrade the RNA.

14. To minimize exposure of a PCR reaction to RNA/DNA contamination that lead to false positives, it is optimal to designate a "clean" room where master mixes can be prepared separate 
from where nucleic acids are extracted and PCR templates added. Additionally designate "clean" pipettes for use solely for master mix preparation and dispensing, and negative control addition.

15. The purpose of the negative control is to monitor the integrity of the master mix, ascertaining that it remains free of contaminating positive PCR template (no amplicon observed in the gel) for the run to be valid.

16. It is best to use a positive control RNA template diluted sufficiently to a working concentration that produces only a moderately strong band/amplicon in the gel. This will minimize the production of large amounts of positive PCR products that build up over time in the environment and often lead to PCR contamination.

17. Take care that the agarose solution does not boil over while melting it in the microwave. To prevent this from occurring, the microwave should be turned off immediately as bubbling starts to occur, the flask taken out and swirled for even mixing of the solution, then heated again in the microwave until the agarose is completely melted. Protective mitts must always be used when handling the flask with the heated/melted agarose.

18. Ethidium bromide is a mutagenic substance. Always wear personal protective gear when working with this chemical.

19. Before pulling out the combs, make sure that the agarose gel is already fully set. The gel at the bottom of the wells will get torn off as the comb is lifted out if the gel is not yet fully set. Prior to use, always check that the gel is intact at the bottom of every well. A hole in the bottom of the well will cause the loaded PCR product to leak out.

20. If using gel combs with smaller teeth, decrease the amount of PCR product+loading dye to be applied, accordingly, to each well, taking care that the product does not overflow out of the well. Overflow will lead to contamination of the neighboring well which may lead to false positives.

21. Bromophenol blue, a common loading dye, migrates at a rate similar to that of a 300 bp DNA fragment.

22. Each SmartCycler II processing block or unit has 16 sites or wells. Each site or well is an independently controlled and programmable I-CORE (Intelligent Cooling/Heating Optical Reaction) module. Up to six blocks may be daisy-chained together and operated with a single computer, mimicking a 96-well reaction set-up. Each block gets designated a letter, from "A" to " $F$ ", in a 6-block set-up.

23. Alternatively, a graph may be created from scratch by clicking "New Graph" at the bottom of the screen, assigning a name to the graph (e.g., FAM Amp curve), then selecting the options 
on the right depending on the purpose of the graph, then click "Save Graph".

24. Changing the "Usage" setting of the nonrelevant dyes, Cy3, TxR, and Cy5, from "Assay" to "Unused" will remove the data columns assigned for these dyes in the Results Table, leaving results displayed only for "FAM", giving a more compact table of results.

25. To chill a SmartCycler reaction tube rack, we recommend just keeping it in the refrigerator $\left(4^{\circ} \mathrm{C}\right)$ and not in the freezer.

26. The Ct (cycle threshold) value is the PCR cycle number at which the fluorescence signal emitted by the generated PCR product is above background noise and crosses the manually set threshold line. The higher the amount of the starting target template in the sample, the lower the Ct value. A negative sample or control will not cross the threshold throughout the run and will have a $\mathrm{Ct}=0$. If the negative control shows a $\mathrm{Ct}>0$, this indicates that there is template contamination in the master mix, and hence the results of the run are not valid. The contamination issue should be addressed and the run repeated.

\section{References}

1. Williams BH, Kiupel M, West KH et al (2000) Coronavirus-associated epizootic catarrhal enteritis in ferrets. J Am Vet Med Assoc 217: 526-530

2. Wise AG, Kiupel M, Maes RK (2006) Molecular characterization of a novel coronavirus associated with epizootic catarrhal enteritis (ECE) in ferrets. Virology 349:164-174

3. Gregori F, Catroxo MHB, Lopes VDS et al (2010) Occurrence of ferret enteric coronavirus in Brazil (preliminary report). Braz J Vet Res Anim Sci São Paulo 47:156-158

4. Provacia LBV, Smits SL, Martina BE et al (2011) Enteric coronavirus in ferrets, the Netherlands. Emerg Infect Dis 17:1570-1571

5. Terada Y, Minami S, Noguchi K et al (2014) Genetic characterization of coronaviruses from domestic ferrets, Japan. Emerg Infect Dis 20:284-287

6. Garner MM, Ramsell K, Morera N et al (2008) Clinicopathologic features of a systemic coronavirus-associated disease resembling feline infectious peritonitis in the domestic ferret (Mustelaputorius). Vet Pathol 45:236-246

7. Juan-Sallés C, Teifke N, Morera N et al (2006) Pathology and immunohistochemistry of a disease resembling feline infectious peritonitis in ferrets (Mustelaputoriusfuro). Proc Am Col Vet Pathol 84:845
8. Martinez J, Ramis AJ, Reinacher M, Perpiñán D (2006) Detection of feline infectious peritonitis virus-like antigen in ferrets. Vet Rec 158:523

9. Martinez J, Reinacher M, Perpiñán D, Ramis A (2008) Identification of group 1 coronavirus antigen in multisystemic granulomatous lesions in ferrets (Musteloputoriusfuro). J Comp Pathol 138:54-58

10. Wise AG, Kiupel M, Garner MM, Clark AK, Maes RK (2010) Comparative sequence analysis of the distal one-third of the genomes of a systemic and an enteric ferret coronavirus. Virus Res 149:42-50

11. Graham E, Lamm C, Denk D et al (2012) Systemic coronavirus-associated disease resembling feline infectious peritonitis in ferrets in the UK. Vet Rec 171:200-201

12. Linsart A, Nicolier A, Sauvaget S (2013) Unusual presentation of systemic coronavirus is in a ferret. PMCAC 48:123-128

13. Michimae $\mathrm{Y}$, Mikami $S$, Okimoto $\mathrm{K}$ et al (2010) The first case of feline infectious peritonitis-like pyogranuloma in a ferret infected by coronavirus in Japan. J Toxicol Pathol 23:99-101

14. Shigemoto J, Muraoka Y, Wise AG et al (2014) Two cases of systemic coronavirus-associated disease resembling feline infectious peritonitis 
in domestic ferrets in Japan. J Exot Pet Med 23:196-100

15. Wise AG, Kiupel M, Maes RK (2011) Emerging coronaviruses of ferrets. In: Abstracts of the XII International Nidovirus Symposium, Traverse City, MI, 4-9 June 2011

16. Chang HW, de Groot RJ, Egberink HF, Rottier PJ (2010) Feline infectious peritonitis: Insights into feline coronavirus pathobiogenesis and epidemiology based on genetic analysis of the viral 3c gene. J Gen Virol 91:415-420

17. Pedersen NC (2009) A review of feline enteric coronavirus infection. J Feline Med Surg 11:225-258

18. Pedersen NC, Liu H, Scarlett J et al (2012) Feline infectious peritonitis: role of the feline coronavirus $3 \mathrm{c}$ gene in intestinal tropism and pathogenicity based upon isolates from resident and adopted shelter cats. Virus Res 165:17-28

19. Parida MM (2008) Rapid and real-time detection technologies for emerging viruses of biomedical importance. J Biosci 33:617-628

20. Ratcliff RM, Chang G, Kok T et al (2007) Molecular diagnosis of medical viruses. Curr Issues Mol Biol 9:87-102

21. Sellon RK (2003) Update on molecular techniques for diagnostic testing of infectious disease. Vet Clin North Am Small Anim Pract 33:677-693

22. Yang S, Rothman RE (2004) PCR-based diagnostics for infectious diseases: uses, limitations, and future applications in acute-care settings. Lancet Infect Dis 4:337-348 